\title{
Enhancement of Visible-Light Photocatalytic Activity of Mesoporous Au-TiO 2 Nanocomposites by Surface Plasmon Resonance
}

\author{
Minghua Zhou, ${ }^{1,2}$ Jun Zhang, ${ }^{2}$ Bei Cheng, ${ }^{2}$ and Huogen $\mathbf{Y u}^{2}$ \\ ${ }^{1}$ Laboratory of Medical Chemistry, Hubei University of Chinese Medicine, Shiyan, Hubei 442000, China \\ ${ }^{2}$ State Key Laboratory of Advanced Technology for Material Synthesis and Processing, Materials College, \\ Wuhan University of Technology, 122 Luoshi Road, Wuhan 430070, China
}

Correspondence should be addressed to Bei Cheng, chengbei2003@yahoo.com.cn and Huogen Yu, yuhuogen@yahoo.cn

Received 30 October 2011; Accepted 2 November 2011

Academic Editor: Jiaguo Yu

Copyright (C) 2012 Minghua Zhou et al. This is an open access article distributed under the Creative Commons Attribution License, which permits unrestricted use, distribution, and reproduction in any medium, provided the original work is properly cited.

\begin{abstract}
Mesoporous $\mathrm{Au}-\mathrm{TiO}_{2}$ nanocomposite plasmonic photocatalyst with visible-light photoactivity was prepared by a simple spray hydrolytic method using photoreduction technique at $90^{\circ} \mathrm{C}$. The prepared samples were characterized by X-ray diffraction, scanning electron microscopy, transmission electron microscopy, and $\mathrm{N}_{2}$ adsorption-desorption isotherms. The formation of hydroxyl radicals $(\bullet \mathrm{OH})$ on the surface of visible-light illuminated $\mathrm{Au}-\mathrm{TiO}_{2}$ nanocomposites was detected by the luminescence technique using terephthalic acid as probe molecules. The photocatalytic activity was evaluated by photocatalytic decolorization of Rhodamine-B (RhB) aqueous solution under visible-light irradiation $(\lambda>420 \mathrm{~nm})$. The results revealed that the $\mathrm{TiO}_{2}$ could be crystallized via spray hydrolysis method, and the photoreduction technique was facilitated to prepare Au nanoparticles in the mesoporous $\mathrm{TiO}_{2}$ at $90^{\circ} \mathrm{C}$. The light absorption, the formation rate of hydroxyl radicals, and photocatalytic decolorization of Rhodamine- $\mathrm{B}$ aqueous solution were significantly enhanced by those embedded Au nanoparticles in the $\mathrm{Au}-\mathrm{TiO}_{2}$ nanocomposites. The prepared $\mathrm{Au}-\mathrm{TiO}_{2}$ nanocomposites exhibit a highly visible-light photocatalytic activity for photocatalytic degradation of $\mathrm{RhB}$ in water, and their photocatalytic activity is higher than that of the pristine $\mathrm{TiO}_{2}$ nanoparticles due to the surface plasmon resonance.
\end{abstract}

\section{Introduction}

Since the discovery of photocatalytic water splitting on $\mathrm{TiO}_{2}$ single-crystal electrodes by Fujishima and Honda in 1972 [1], nanosized $\mathrm{TiO}_{2}$ semiconductor has been always regarded as one of the most promising photocatalysts in practical applications, especially water cleaning and removal of volatile organic compounds (VOCs) in air, due to its high photocatalytic activity, chemical stability, low cost, and nontoxicity [2-12]. Recently, highly dispersed noble metal nanoparticles with desirable morphologies have attracted great attention due to their unusual catalytic, electric, optical properties and surface plasmon absorption, and their widespread potential usefulness in diverse fields such as biomedicine, photocatalysis, energy conversion, and storage and nanodevices [13-19]. Some investigations have indicated that nobel metal Au nanoparticles deposited on $\mathrm{TiO}_{2}$ surface can obviously enhance the photocatalytic performance via suppressing the recombination of electron-hole pairs, and also extending the light response in the visible region $[14,20,21]$. However, the practical applicability of such a composite structure is limited owing to exposing both the $\mathrm{Au}$ nanoparticles to reactants and the surrounding, while the corrosion or dissolution of the Au nanoparticles during the photocatalytic reaction is likely to limit the usage of $\mathrm{Au}$, especially for long-term working [13]. To overcome this shortcoming, the Au nanoparticles embeded or enwrapped by the $\mathrm{TiO}_{2}$ aggregates have attracted considerable attention, and significant advances have been made in recent years. The $\mathrm{TiO}_{2}$ aggregates offer protection for Au nanoparticles against dissolution, photocorrosion, and chemical corrosion under extreme conditions, as well as being used for decomposition of dye wastewater. Among the various phases of $\mathrm{TiO}_{2}$, anatase has proven to be the most suitable one due to its 
two distinctive performances. One is that the photogenerated electrons of anatase can rapidly reduce $\mathrm{Au}$ ions at interface [22]. The other is that the conduction band of anatase can transfer the photogenerated electrons of the excited $\mathrm{Au}$ to adsorbed $\mathrm{O}_{2}$ and then to form active superoxide radical anions [23-25].

Several techniques, such as sol-gel method, chemical vapor deposition, laser vaporization, modified impregnation, precipitation-reduction, and photoreduction, have been developed to design and modulate the $\mathrm{Au}-\mathrm{TiO}_{2}$ composite nanoparticles. The preferred and versatile method is the sol-gel process, which has many advantages, such as simple equipment required, flexible control of pore structures, and the concentration of $\mathrm{Au}$ [26-30]. Usually, the $\mathrm{TiO}_{2}$ aggregates obtained by this method are amorphous in nature and calcination temperatures higher than $400^{\circ} \mathrm{C}$ are required to realize the phase transformation from amorphous to anatase. However, such high calcination temperatures will not only lead to the increase of crystallite size and the decrease of specific surface areas and pore volume, but also induce the heat-aggregation of Au nanoparticles. Generally, the Au particles have exhibited highly catalytic activity only with smaller nanoscale size [31-34]. So, in order to obtain crystallized $\mathrm{Au}-\mathrm{TiO}_{2}$ composite nanoparticles with higher specific surface areas and pore volume, the temperature of phase transformation from amorphous to anatase must be lowered.

In this paper, a novel and simple method, a low-temperature spray hydrolysis assisted with photoreduction tech nique, was proposed for the synthesis of $\mathrm{Au}-\mathrm{TiO}_{2}$ nanocomposites. The Au nanoparticles (Au colloids) were prepared by photoreduction technique using a $350 \mathrm{~W}$ xenon lamp as a light source. $\mathrm{Au}-\mathrm{TiO}_{2}$ nanocomposites were prepared by spraying the mixed solution of $\mathrm{Ti}\left(\mathrm{OC}_{4} \mathrm{H}_{9}\right)_{4}$ and EtOH into hot distilled water in the presence of Au nanoparticles (ca. $\left.90^{\circ} \mathrm{C}\right)$. The formation of hydroxyl radicals $(\bullet \mathrm{OH})$ on the surface of visible-light illuminated $\mathrm{Au}-\mathrm{TiO}_{2}$ composite samples was detected by the photoluminescence technique using terephthalic acid as probe molecules. The photocatalytic activity of the $\mathrm{Au}-\mathrm{TiO}_{2}$ composite samples was evaluated by photocatalytic decolorization of RhB aqueous solution under visible-light irradiation $(\lambda>420 \mathrm{~nm})$.

\section{Experimental}

2.1. Preparation of Au Nanoparticles. All the involved chemicals in this study were purchased from Shanghai Chemical Reagent Co., Ltd, and used without further purification. Typically, $10 \mathrm{~mL}$ aqueous solution of sodium citrate $(38.8 \mathrm{mM})$ was added into $100 \mathrm{~mL}$ aqueous solution of $\mathrm{HAuCl}_{4} \cdot 4 \mathrm{H}_{2} \mathrm{O}$ (1 mM) under vigorous stirring. A $350 \mathrm{~W}$ xenon lamp was used a light source to irradiate the mixed solution during the reduction process. The color of the solution was gradually changed from light-yellow to fuchsia. After irradiation for another $30 \mathrm{mins}$, it was cooled to room temperature.

2.2. Preparation of $\mathrm{Au}-\mathrm{TiO}_{2}$ Composite Nanoparticles. In a typical synthesis [35], $10 \mathrm{~mL}$ of mixed solution of Tetrabutyl titanate (TBOT) and ethanol (volume ratio of TBOT to ethanol, 1:4) was sprayed into a $250 \mathrm{~mL}$ beaker containing $200 \mathrm{~mL}$ hot distilled water $\left(90^{\circ} \mathrm{C}\right)$, in which the added above $\mathrm{Au}$ nanoparticles was used as Au source. The corresponding nominal atomic ratio of $\mathrm{Au}$ to $\mathrm{Ti}$, which hereafter was designated as $R_{\mathrm{Au}}$, was $0.003,0.006,0.015,0.030$, and 0.060 nominal atomic \% (at. \%). After further stirring for $2 \mathrm{~h}$ at $90^{\circ} \mathrm{C}$, the resultant mixed solution was aged for $2 \mathrm{~h}$ at $90^{\circ} \mathrm{C}$. The aged wet precipitates were filtrated, rinsed with distilled water and absolute alcohol for two times. Then the precipitates were dried in a vacuum oven at $80^{\circ} \mathrm{C}$ for $10 \mathrm{~h}$ and finally ground to obtain $\mathrm{Au}-\mathrm{TiO}_{2}$ composite samples. As a control experiment, the pristine $\mathrm{TiO}_{2}$ product was also prepared under the same condition but without adding $\mathrm{Au}$ nanoparticles.

2.3. Characterization. X-ray diffraction (XRD) patterns obtained on a D/Max-RB X-ray diffractometer (Rigaku, Japan) using $\mathrm{Cu} \mathrm{K} \alpha$ irradiation at a scan rate $(2 \theta)$ of $0.05^{\circ} \mathrm{s}^{-1}$ were used to determine the phase structure of the obtained samples. The average crystallite sizes of anatase were determined according to the Scherrer equation using the full width at half maximum (FWHM) data of anatase phase after correcting the instrumental broadening. Morphology observation was performed on a S-4800 field emission scanning electron microscope (FESEM, Hitachi, Japan). Transmission electron microscopy (TEM) and high-resolution transmission electron microscopy (HRTEM) observation were conducted using a JEM 2100F microscope at an accelerating voltage of $200 \mathrm{kV}$. The Brunauer-Emmett-Teller surface areas $\left(S_{\mathrm{BET}}\right)$ of the samples were analyzed by nitrogen adsorption in a Micromeritics ASAP 2020 nitrogen adsorption apparatus (USA). All the samples were degassed at $80^{\circ} \mathrm{C}$ prior to nitrogen adsorption measurements. The BET surface area was determined by a multipoint BET method using the adsorption data in the relative pressure $\left(P / P_{0}\right)$ range of 0.05 to 0.30 . Desorption isotherm was used to determine the pore size distribution via the Barret-Joyner-Halender (BJH) method, assuming a cylindrical pore modal [36]. The nitrogen adsorption volume at the relative pressure $\left(P / P_{0}\right)$ of 0.994 was used to determine the pore volume and average pore size. UV-visible absorbance spectra of Au$\mathrm{TiO}_{2}$ composite nanoparticles were obtained for the drypressed disk samples with a UV-visible spectrophotometer (UV-2550, Shimadzu, Japan). $\mathrm{BaSO}_{4}$ was used as a absorption standard in the UV-visible absorbance experiment. Xray photoelectron spectroscopy (XPS) measurements were performed on a Kratos XSAM800 XPS system with $\mathrm{Cu} \mathrm{K} \alpha$ source. During the experiments the pressure in the chambers was about $10^{-7} \mathrm{~Pa}$. All the binding energies were referenced to the C1s peak at $284.8 \mathrm{eV}$ of the surface adventitious carbon.

2.4. Analysis of Hydroxyl Radical $(\bullet \mathrm{OH})$. The formation of hydroxyl radical $(\bullet \mathrm{OH})$ on the surface of photoirradiated $\mathrm{Au}-\mathrm{TiO}_{2}$ is detected by photoluminescence (PL) technique using terephthalic acid as a probe molecule. Terephthalic acid readily reacts with $\bullet \mathrm{OH}$ to produce highly fluorescent product, 2-hydroxyterephthalic acid [37, 38]. This technique has 
been widely used in radiation chemistry, sonochemistry, and biochemistry [37-39] for the detection of $\bullet \mathrm{OH}$ generated in water. The intensity of the PL peak of 2-hydroxyterephtalic acid is in proportional to the amount of $\bullet \mathrm{OH}$ radicals produced in water [37-39]. The optimal concentration of terephthalic acid solution was about $5 \times 10^{-4} \mathrm{M}$ in a diluted $\mathrm{NaOH}$ aqueous solution $\left(2 \times 10^{-3} \mathrm{M}\right)$. This method relies on the PL signal at $425 \mathrm{~nm}$ of the hydroxylation of terephthalic acid with $\bullet \mathrm{OH}$ generated at the water $/ \mathrm{TiO}_{2}$ interface. The method is rapid, sensitive, and specific, only needs a simple standard PL instrumentation.

In order to measure the concentration of hydroxyl radical $(\bullet \mathrm{OH})$ of the prepared samples, the typical experimental procedures are as follows $\mathrm{Au}-\mathrm{TiO}_{2}$ composite samples were weighed and then uniformly dispersed into $20 \mathrm{~mL}$ distilled water under 10 min ultrasonic shaking to form $\mathrm{TiO}_{2}$ suspension. The photocatalyst was prepared by coating the above aqueous suspension of $\mathrm{TiO}_{2}$ samples onto one dish with a diameter of about $9.0 \mathrm{~cm}$. The weight of catalysts used for each experiment was kept $0.10 \mathrm{~g}$. The dishes containing composite powders were dried in an oven at $80^{\circ} \mathrm{C}$ for about $2 \mathrm{~h}$ to evaporate the water and then cooled to room temperature before being used. A $20 \mathrm{~mL}$ of the $5 \times 10^{-4} \mathrm{M}$ terephthalic acid aqueous solution with a concentration of 2 $\times 10^{-3} \mathrm{M} \mathrm{NaOH}$ was added into the coated dish, which was then irradiated with a $15 \mathrm{~W}$ daylight lamp. In order to ensure only the visible light irradiation, each dish was covered with an ultraviolet cutoff filter $(\lambda>420 \mathrm{~nm})$. PL spectra of generated 2-hydroxyterephthalic acid were measured on a fluorescence spectrophotometer (F-7000, Hitachi, Japan) using a $315 \mathrm{~nm}$ excitation wavelength at a scan speed of $1200 \mathrm{~nm} \mathrm{~min}{ }^{-1}$ with the PMT voltage of $700 \mathrm{~V}$. The width of excitation slit and emission slit were $1.0 \mathrm{~nm}$.

2.5. Photocatalytic Activity. The visible-light photocatalytic activity of the $\mathrm{Au}-\mathrm{TiO}_{2}$ composite samples was evaluated by photocatalytic decolorization of RhB aqueous solution. The detailed procedure was similar to our previous works [40]. Here, the weight of the photocatalyst used was kept at about 0.1 g. A $15 \mathrm{~W}$ daylight lamp $(6 \mathrm{~cm}$ above the dishes, just mentioned above) was used as a light source and each dish was covered with an ultraviolet cutoff filter. The absorbance of RhB was determined by a UV-visible spectrophotometer (UV2550, Shimadzu, Japan). The concentration of $\mathrm{RhB}(c)$ was in proportion to the light absorbance $(A)$ at $550 \mathrm{~nm}$ according to Beer-Lambert law. As for the Rhodamine- $\mathrm{B}$ aqueous with a concentration of $1 \times 10^{-5} \mathrm{M}$, its photocatalytic decolorization is a pseudofirst-order reaction and its kinetics may be expressed as $[41,42]$ :

$$
\ln \frac{A_{0}}{A_{t}}=k t,
$$

where $k$ is the apparent rate constant, and $A_{0}$ and $A_{t}$ are the initial and reaction absorbance of $\mathrm{RhB}$ aqueous, respectively.

\section{Results and Discussion}

3.1. Phase Structures. XRD was used to investigate the changes of phase structure of the as-prepared $\mathrm{Au}-\mathrm{TiO}_{2}$ nano-

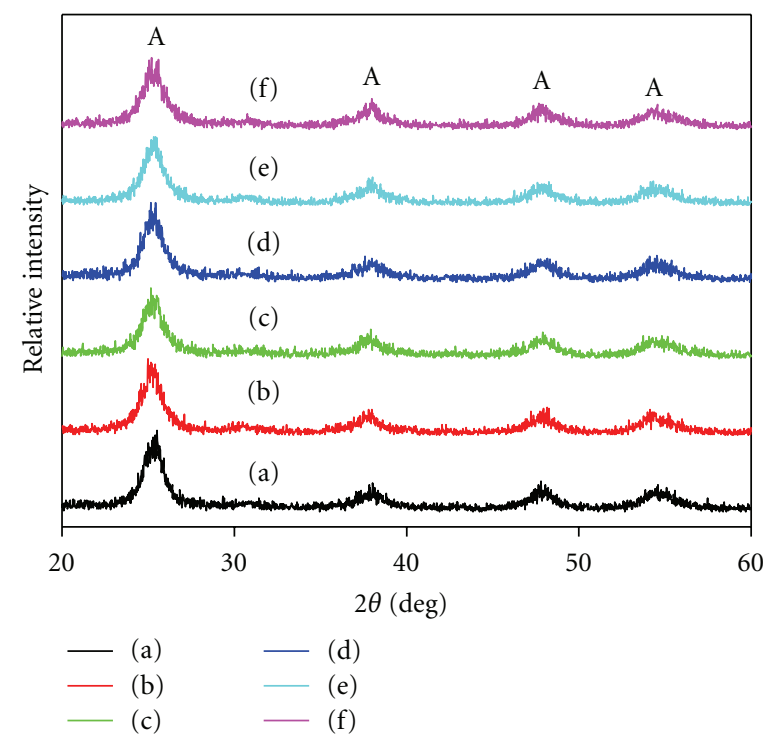

FIGURE 1: XRD patterns of the $\mathrm{Au}-\mathrm{TiO}_{2}$ composite powders prepared with different $R_{\mathrm{Au}}$ : (a) 0, (b) 0.003, (c) 0.006, (d) 0.015, (e) 0.030 , and (f) 0.060 .

composites and pure $\mathrm{TiO}_{2}$. Figure 1 shows the effects of $R_{\mathrm{Au}}$ on phase structures of the $\mathrm{Au}-\mathrm{TiO}_{2}$ composite powders. It can be seen that the diffraction peaks of all samples were indexed with the anatase phase of $\mathrm{TiO}_{2}$, which was consistent with our previous work [35]. With increasing the $R_{\mathrm{Au}}$, the intensities of anatase peaks steadily become weaker and the width of the diffraction peaks $\left(2 \theta=25.3^{\circ}\right)$ of anatase slightly became wider. This was probably due to the fact that $\mathrm{Au}$ nanoparticles suppress the crystallization of $\mathrm{TiO}_{2}$ xerogel powders. However, the XRD diffraction peaks of Au could not be seen in the Figure 1, which was attributed to the fact that the content of Au was so low that it could not be detected by XRD diffractometer.

The microstructure of the $\mathrm{Au}-\mathrm{TiO}_{2}$ composite powder was further studied by TEM and HRTEM. Figure 2(a) shows the TEM image of the $R_{\mathrm{Au}}-0.060$ composite sample. It can be observed from Figure 2(a) that the nanocrystallite appears as an agglomerated status, and mesoporous structures without a long-range order. The size of the primary particles estimated from the TEM image was about $6 \pm 1 \mathrm{~nm}$, which was in accord with the value of crystallize size $(6.0 \mathrm{~nm})$ calculated from XRD pattern using the Scherrer equation (as shown in Table 1). Figure 2(b) shows the corresponding HRTEM image of the $R_{\mathrm{Au}}-0.060$ composite powder. Further observation shows that all the particles are crystallized as evidence from the well-resolved $\mathrm{Au}$ (111) $(0.25 \mathrm{~nm})$ and $\mathrm{TiO}_{2}(101)(0.35 \mathrm{~nm})$ crystalline lattices as shown in the inset of Figure 2(b) [42-44].

Effects of the $R_{\mathrm{Au}}$ on the surface morphology of the prepared $\mathrm{Au}-\mathrm{TiO}_{2}$ composite powders were characterized by FESEM. Figure 3 illustrates FESEM images of all the $\mathrm{Au}-\mathrm{TiO}_{2}$ composite powders, indicating their nonuniform growth and particle size distribution in spherical morphology, which changed slightly with the different Au modification. This agglomeration process was attributed to Van der Waals 


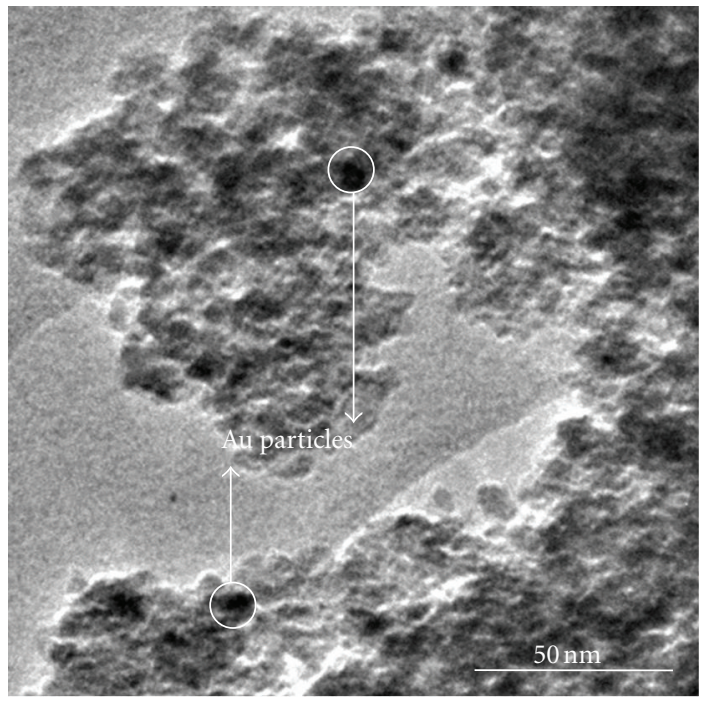

(a)

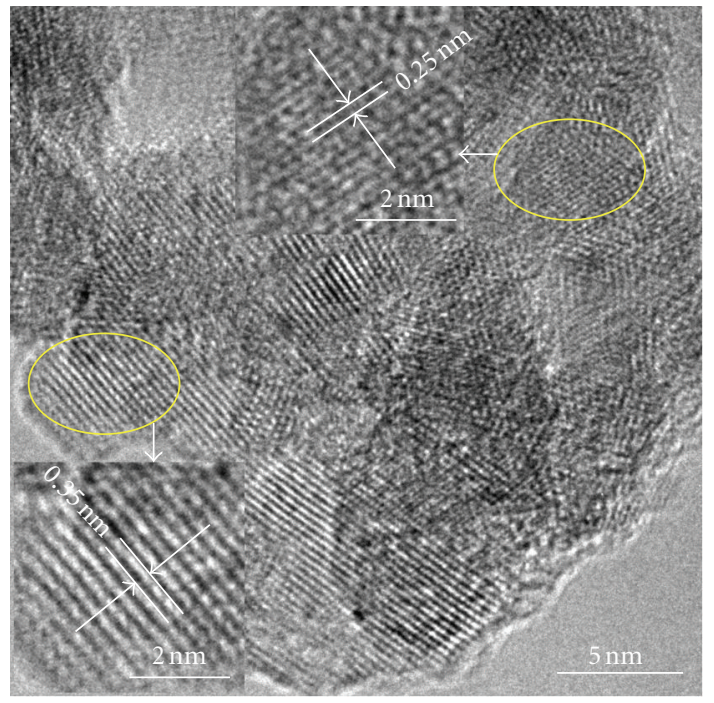

(b)

Figure 2: TEM (a) and HRTEM (b) images of the $R_{\mathrm{Au}}-0.060$ composite powder.

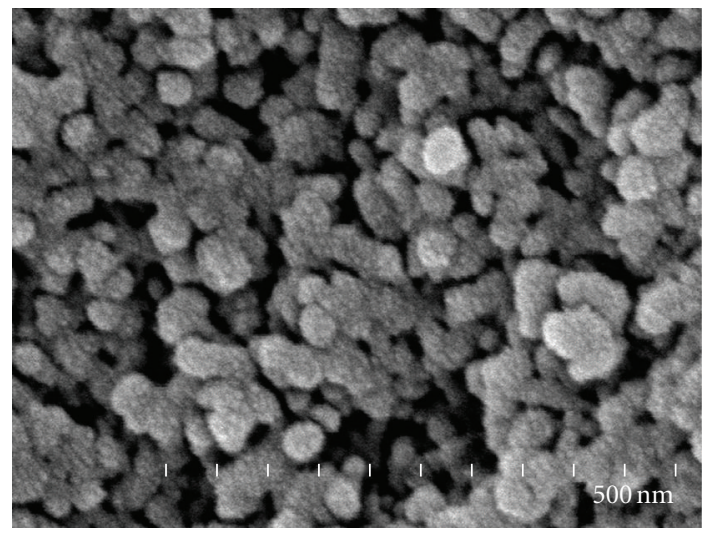

(a)

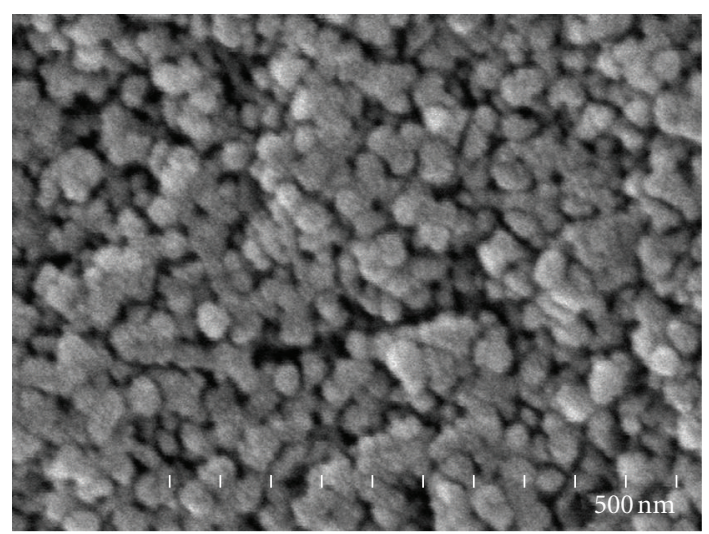

(c)

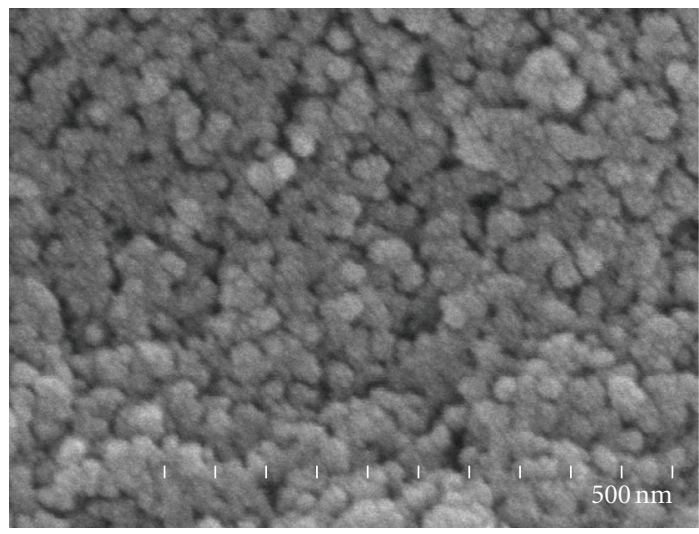

(b)

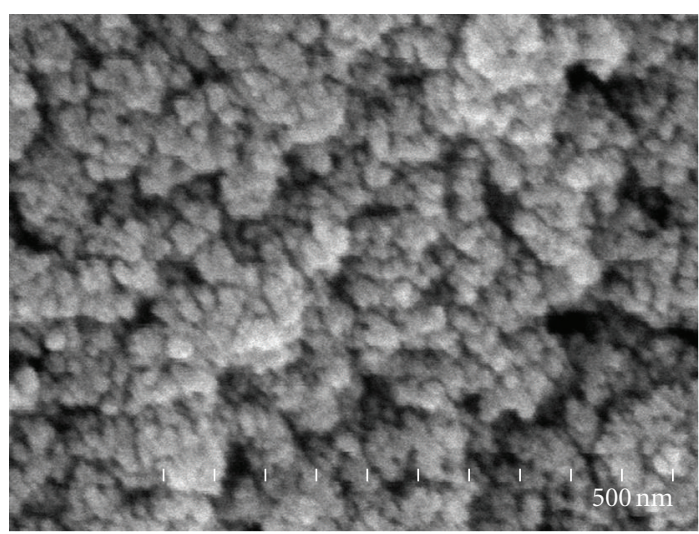

(d)

Figure 3: FESEM images of the $\mathrm{Au}-\mathrm{TiO}_{2}$ composite powders prepared with different $R_{\mathrm{Au}}$ : (a) 0 , (b) 0.003 , (c) 0.015 , and (d) 0.060 . 


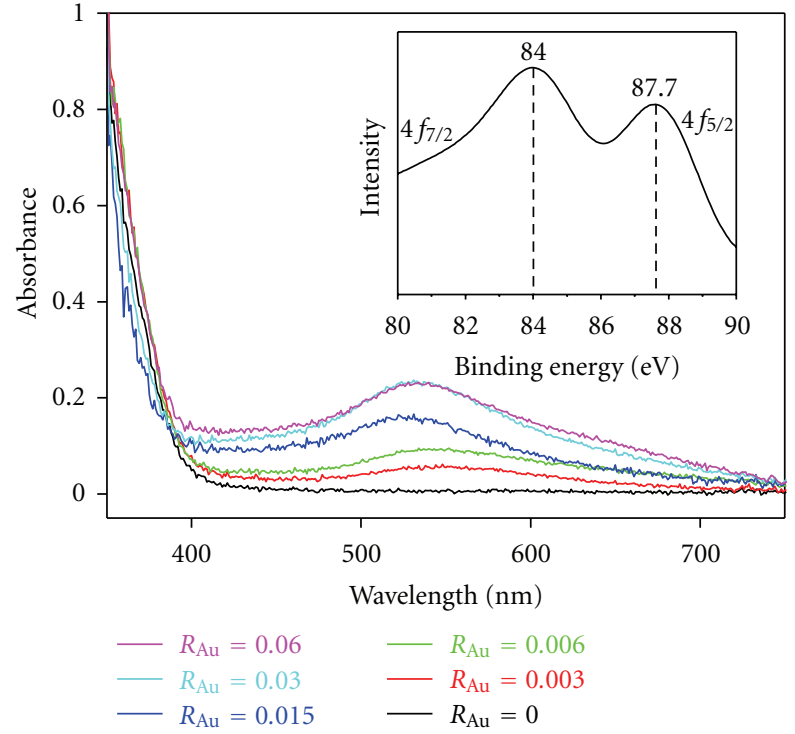

FIgURE 4: UV-Vis absorbance spectra of the $\mathrm{Au}-\mathrm{TiO}_{2}$ composite powders prepared with different $R_{\mathrm{Au}}$ and (inset) high-resolution XPS spectrum of $\mathrm{Au} 4 \mathrm{f}$ of the $R_{\mathrm{Au}}-0.060$ sample.

forces. In order to reduce the surface energy, the primary particles have a tendency to form an agglomerate, by forming nearly spherical or equiaxed agglomerates, in a minimum surface-to-volume ratio and hence minimum surface free energy can be achieved. All the $\mathrm{Au}-\mathrm{TiO}_{2}$ composite powders are composed of such nanoscale particles, indicating that the composite powders prepared by this low-temperature spray method possess large specific surface area and the high volume fraction of atoms located both on the surface and at the grain boundaries. Therefore, this $\mathrm{Au}-\mathrm{TiO}_{2}$ composite nanocrystalline can provide more active sites for catalysis. Furthermore, all the $\mathrm{Au}-\mathrm{TiO}_{2}$ composite powders have roughness surface accompanied with many mesopores. In general, such nanoscale particles with such diameter will be more promising because light harvesting can be further enhanced. In this respect, nanocrystalline $\mathrm{Au}-\mathrm{TiO}_{2}$ composite particles with this special morphology can enhance the absorbance of the light resulting in the enhancement of photocatalytic activity. Further observations indicated that the powders without Au nanoparticles modification (pristine $\mathrm{TiO}_{2}$ ) have large particles. With increasing the $R_{\mathrm{Au}}$, the average size of aggregated particles decreases.

3.2. UV-Visible Absorbance Spectra. Figure 4 shows UV-Vis absorbance spectra for the composite $\mathrm{Au}-\mathrm{TiO}_{2}$ samples. A significant increase at wavelengths longer than $400 \mathrm{~nm}$ could be attributed to the plasmon resonance absorbance of the $\mathrm{Au}$ nanoparticles $[22,44]$. The $\mathrm{Au}-\mathrm{TiO}_{2}$ composite powders compared with the pristine $\mathrm{TiO}_{2}$ powders have a slight red shift in the band gap transition. Moreover, a characteristic absorbance signal at $530 \mathrm{~nm}$ give the valid evidence that the Au phase existed in the products, though direct observation by XRD failed [24, 33, 45-47]. Further observation indicates that the intensity of the surface plasmon absorbance increase

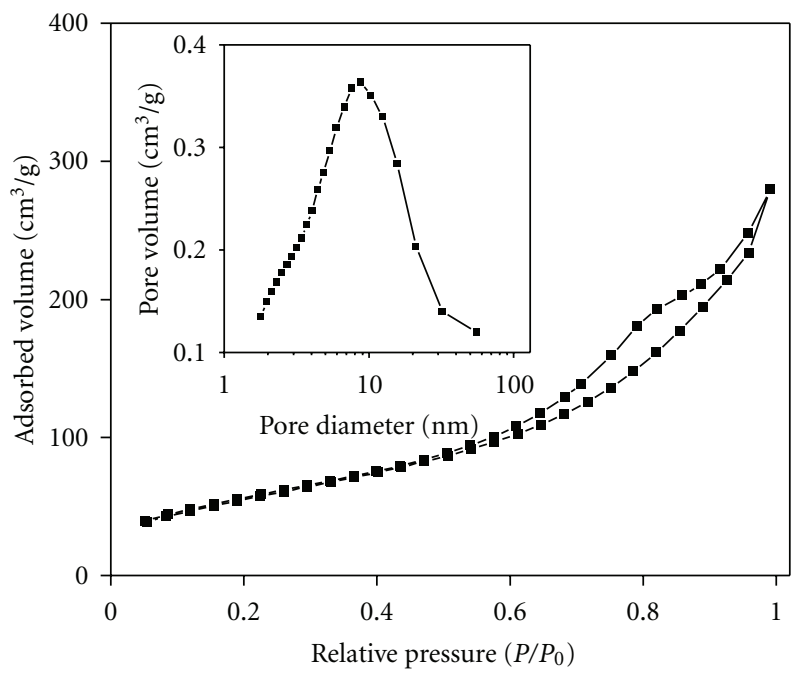

FIGURE 5: $N_{2}$ adsorption-desorption isotherm and pore size distribution curve (inset) of the $R_{\mathrm{Au}}-0.015$ composite powder.

with increasing $R_{\mathrm{Au}}$, which is probably due to the more Au nanoparticles embeded in $\mathrm{TiO}_{2}$ aggregates. The enhanced light absorption in the visible light region can therefore increase the quantities of photogenerated electrons and holes that participate in photocatalytic reactions. In order to verify the chemical state of $\mathrm{Au}$ element in the $\mathrm{Au}$ $\mathrm{TiO}_{2}$ composite powders, the $R_{\mathrm{Au}}-0.060$ sample was also characterized with XPS. High-resolution XPS spectrum (inset in Figure 4) shows binding energy of $\mathrm{Au}_{4 f 7 / 2}$ at 84.0 and $\mathrm{Au}_{4 f 5 / 2}$ at $87.7 \mathrm{eV}$, which are significantly different from $\mathrm{Au}_{4 f 7 / 2}^{+}(84.6 \mathrm{eV})$ and $\mathrm{Au}_{4 f 7 / 2}^{3+}(87.0 \mathrm{eV})$. The result suggests that the Au species is in the metallic state $[25,44,48,49]$.

3.3. BET Specific Surface Areas and Pore Structure. All the prepared $\mathrm{Au}-\mathrm{TiO}_{2}$ composite powders have similar nitrogen adsorption-desorption isotherms and pore size distribution curves. Therefore, Figure 5 only presents the nitrogen adsorption-desorption isotherm and pore size distribution (inset) of the $R_{\mathrm{Au}}-0.015$ sample. It can be seen that isotherm was of types IV [36]. At high relative pressure range from 0.5 to 1.0 , the isotherm exhibits a hysteresis loop of type $\mathrm{H} 2$ associated with the ink bottle pores, indicating that the powders contain mesopores due to the aggregation of crystallites [4-6]. The corresponding pore size distribution curve of the $R_{\mathrm{Au}}-0.015$ sample is also shown in inset of Figure 5. It can be seen that the $R_{\mathrm{Au}}-0.015$ sample exhibits a narrow pore size distribution with the average pore diameters about $5.7 \mathrm{~nm}$.

Table 1 shows the effects of $R_{\mathrm{Au}}$ on the physical properties of the $\mathrm{Au}-\mathrm{TiO}_{2}$ composite powders. It can be seen that all the prepared samples possess large specific surface area $\left(S_{\mathrm{BET}}>200 \mathrm{~m}^{2} / \mathrm{g}\right)$ and big pore volume $\left(V_{p}>0.30 \mathrm{~cm}^{3} / \mathrm{g}\right)$. With increasing $R_{\mathrm{Au}}$, the average pore sizes decrease from 8.1 to $5.4 \mathrm{~nm}$ while the specific surface area and pore volume change slightly. Generally, the heterogeneous photocatalysis is a surface-based process, and therefore a large surface area has positive effects on such a process. A larger surface 


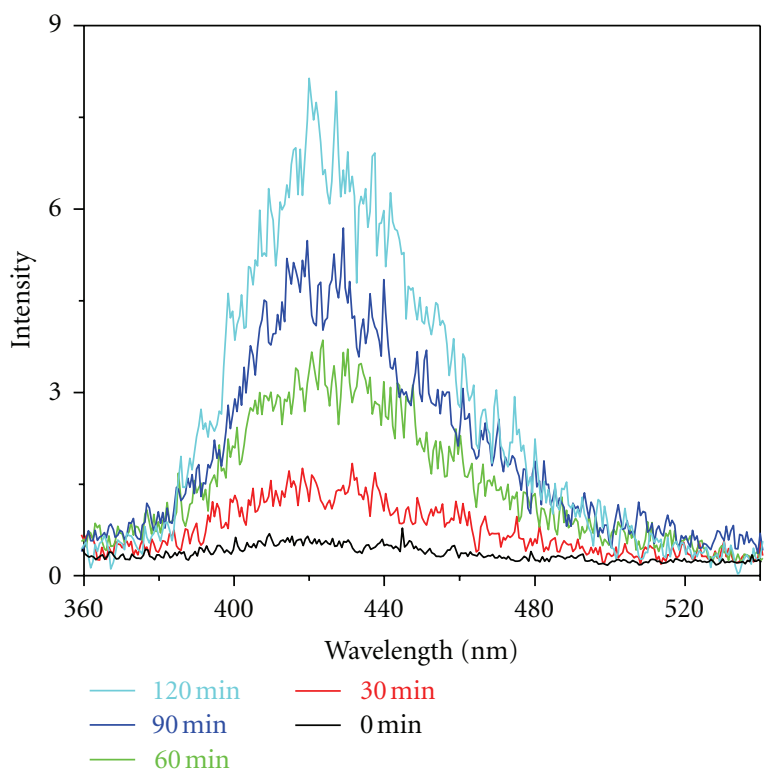

(a)

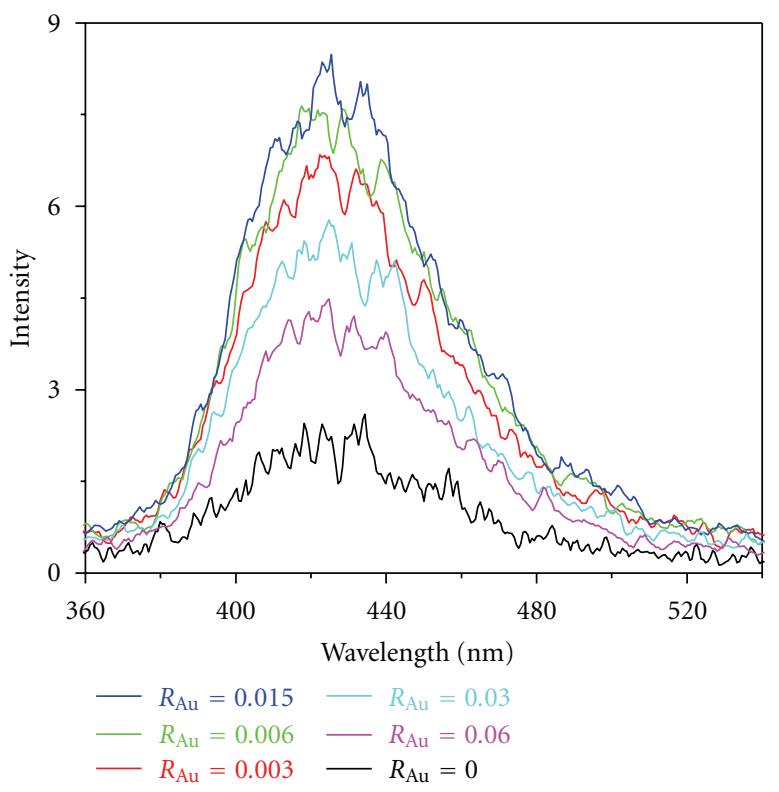

(b)

FIGURE 6: (a) Fluorescence spectral changes with irradiation time on $R_{\mathrm{Au}}-0.015$ sample and (b) the dependence of the fluorescence intensity on $R_{\mathrm{Au}}$ at a fixed $120 \mathrm{~min}$ under visible-light irradiation.

area provides more surface active sites for the adsorption of reactant molecules, which thus make the photocatalytic process more efficient [50-53]. Moreover, the porous structure is believed to facilitate the transporting of reactant molecules and products through the interior space due to the interconnected porous networks, and it favor the harvesting of exciting light due to enlarged surface area and multiple scattering within the porous framework [54-56].

3.4. Hydroxyl Radical Analysis. The PL emission spectrum excited at $315 \mathrm{~nm}$ of terephthalic acid solution was measured

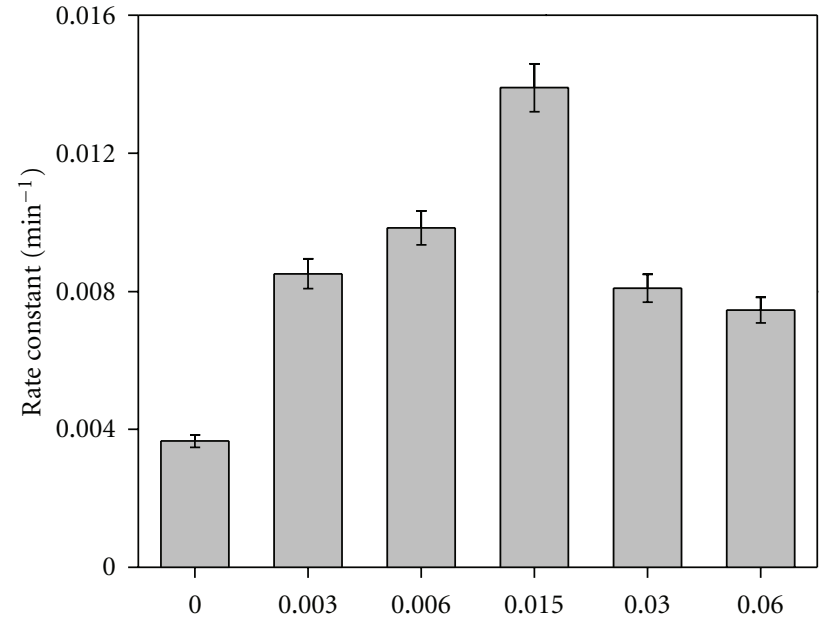

FIGURE 7: Dependence of apparent rate constants $(k)$ of the $\mathrm{Au}-\mathrm{TiO}_{2}$ composite samples on the $R_{\mathrm{Au}}$.

every $30 \mathrm{~min}$ under visible-light irradiation. Figure 6(a) shows the changes of PL spectra of terephthalic acid solution with irradiation time. It can be seen that a gradual increase in PL intensity at wavelength range of $360-540 \mathrm{~nm}$ is observed with increasing irradiation time. Moreover, the generated spectra have the identical shape and peak position (at $425 \mathrm{~nm}$ ). However, no PL increase is observed in the absence of visible-light or $\mathrm{TiO}_{2}$ samples. This suggests that the signal of PL is only caused by the reaction of terephthalic acid with - $\mathrm{OH}$ formed on the interface of the $\mathrm{Au}-\mathrm{TiO}_{2} /$ water during visible-light irradiation $[37,38]$.

Generally, the greater the formation rate of $\bullet \mathrm{OH}$ radicals is, the higher separation efficiency of electron-hole pairs is achieved. So, the photocatalytic activity is in positive correlation to the formation rate of $\bullet \mathrm{OH}$ radicals, namely, a faster formation rate of $\bullet \mathrm{OH}$ radicals leads to a higher photocatalytic activity [38]. Figure 6(b) shows the dependence of PL intensity against irradiation time. It can be easily seen that at a fixed time $(120 \mathrm{~min})$, the formation rate of - $\mathrm{OH}$ radicals on the $\mathrm{Au}-\mathrm{TiO}_{2}$ composite powders is larger than that of the pristine $\mathrm{TiO}_{2}$. This implies that the $\mathrm{Au}-\mathrm{TiO}_{2}$ composite powders have higher photocatalytic activity than the pristine $\mathrm{TiO}_{2}$. Further observation shows that the order of the formation rate of $\bullet \mathrm{OH}$ radicals formed on the surface of as-prepared samples is as follows: $R_{\mathrm{Au}}-0.015>R_{\mathrm{Au}}-0.006$ $>R_{\mathrm{Au}}-0.003>R_{\mathrm{Au}}-0.030>R_{\mathrm{Au}}-0.060>R_{\mathrm{Au}}-0$ (pristine $\mathrm{TiO}_{2}$ ), which suggests that the $R_{\mathrm{Au}}$ influences the formation rate of $\bullet \mathrm{OH}$ radicals and there is an optimum ratio of $\mathrm{Au}$ to $\mathrm{TiO}_{2}$.

3.5. Photocatalytic Activity of the $\mathrm{Au}-\mathrm{TiO}_{2}$ Composite Powders. The photocatalytic activity of the $\mathrm{Au}-\mathrm{TiO}_{2}$ composite powders was evaluated by photocatalytic decolorization of Rhodamine- $\mathrm{B}$ aqueous solution under visible-light irradiation $(\lambda>420 \mathrm{~nm})$ at room temperature. Figure 7 shows the relationship between the apparent rate constants $(k)$ and $R_{\mathrm{Au}}$. It can be seen that the $R_{\mathrm{Au}}$ has a great effect on the photocatalytic activity of the composite samples. Without 
TABLE 1: Effects of $R_{A u}$ on physical properties of the $\mathrm{Au}-\mathrm{TiO}_{2}$ composite powders.

\begin{tabular}{lcccccc}
\hline Sample $\left(R_{\mathrm{Au}}\right)$ & Phase content & ${ }^{\mathrm{a}}$ Crystalline size $/ \mathrm{nm}$ & ${ }^{\mathrm{b}} S_{\mathrm{BET}} \mathrm{m}^{2} / \mathrm{g}$ & ${ }^{\mathrm{c}} V_{p} \mathrm{~cm}^{3} / \mathrm{g}$ & ${ }^{c}$ Porosity $(\%)$ & ${ }^{\mathrm{c}}$ Average pore size/nm \\
\hline 0 & Anatase & 6.7 & 235.5 & 0.57 & 69.0 & 8.1 \\
0.003 & Anatase & 6.7 & 208.4 & 0.46 & 64.2 & 7.5 \\
0.006 & Anatase & 6.5 & 211.7 & 0.34 & 57.0 & 7.1 \\
0.015 & Anatase & 6.5 & 205.0 & 0.43 & 62.6 & 5.7 \\
0.030 & Anatase & 6.3 & 215.9 & 0.38 & 59.7 & 5.8 \\
0.060 & Anatase & 6.0 & 212.4 & 0.34 & 57.0 & 5.4 \\
\hline
\end{tabular}

${ }^{a}$ : Average crystalline size of $\mathrm{TiO}_{2}$ was determined on the basis of the broadening of the anatase $\{101\}$ diffraction peak using the Scherrer equation.

b: The BET surface area was determined by multipoint BET method using the adsorption data in the relative pressure $\left(P / P_{0}\right)$ range of $0.05-0.2$.

${ }^{c}$ : Pore volume, porosity, and average pore size were determined by nitrogen adsorption volume at the relative pressure of 0.994 .

Au modification, the prepared pristine $\mathrm{TiO}_{2}$ powders have the poor visible-light photocatalytic activity presumably due to the self-sensitization of $\mathrm{RhB}$ molecules, which extends the absorption of titania into the visible-light region [57]. Importantly, the photocatalytic activity of all $\mathrm{Au}-\mathrm{TiO}_{2}$ samples is higher than that of pristine $\mathrm{TiO}_{2}$. Further observation shows the reaction rate increases with the increasing of $\mathrm{Au}$ content when the value of $R_{\mathrm{Au}}$ is below 0.015 , and the $R_{\mathrm{Au}}$ 0.015 sample has the best photocatalytic activity among these samples. Therefore, the appropriate modification of the gold nanoparticles can enhance the photocatalytic activity of $\mathrm{TiO}_{2}$ remarkably, which is ascribed to the synergetic effect of the dye-photosensitized and the surface plasmon resonance of $\mathrm{Au}$ nanoparticles in the $\mathrm{Au}-\mathrm{TiO}_{2}$ nanocomposites.

The possible photocatalytic enhanced mechanism of the $\mathrm{Au}-\mathrm{TiO}_{2}$ nanocomposite powders can be explained according to the recently reported mechanism $[4,15,22,47]$. The noble metal nanoparticles can be photoexcited by the visible light due to their plasmon resonance. Under visible-light irradiation, the electrons and holes can be formed on the surface of the Au nanoparticles, and then they are immediately separated via the following processes. The electrons transfer to the adsorbed oxygen molecules via the conduction band of $\mathrm{TiO}_{2}$ and then are trapped through formation of superoxide radical anions. The superoxide radicals and the trapped electrons can combine to produce $\mathrm{H}_{2} \mathrm{O}_{2}$, finally forming hydroxyl radicals. Both hydroxyl radical and superoxide radical anions are strong oxidants which can oxidize the organic molecules (RhB) on the surface of the composite powders, resulting in the formation of intermediate organic species and subsequently complete oxidation of these species to water and carbon dioxide. These improvements would be beneficial to the photooxidation of $\mathrm{RhB}$ using the $\mathrm{Au}$ modified $\mathrm{TiO}_{2}$ under visible-light irradiation. When the $R_{\mathrm{Au}}$ reaches 0.030 , the $\mathrm{Au}-\mathrm{TiO}_{2}$ composite powders show relatively lower photocatalytic activity, which is probably due to the fact that more Au nanoparticles may act as the centers of electron-hole recombination and reduce quantum efficiency [44].

Figure 8 shows the change of absorption spectra of $\mathrm{RhB}$ aqueous solution during its visible-light photocatalytic decolorization using the $R_{\mathrm{Au}}-0.015$ sample as the photocatalyst. It can be seen that the absorption peak at $\lambda=550 \mathrm{~nm}$ drops gradually with increasing visible-light irradiation time. After visible-light irradiation for ca. 180 minutes, the absorp-

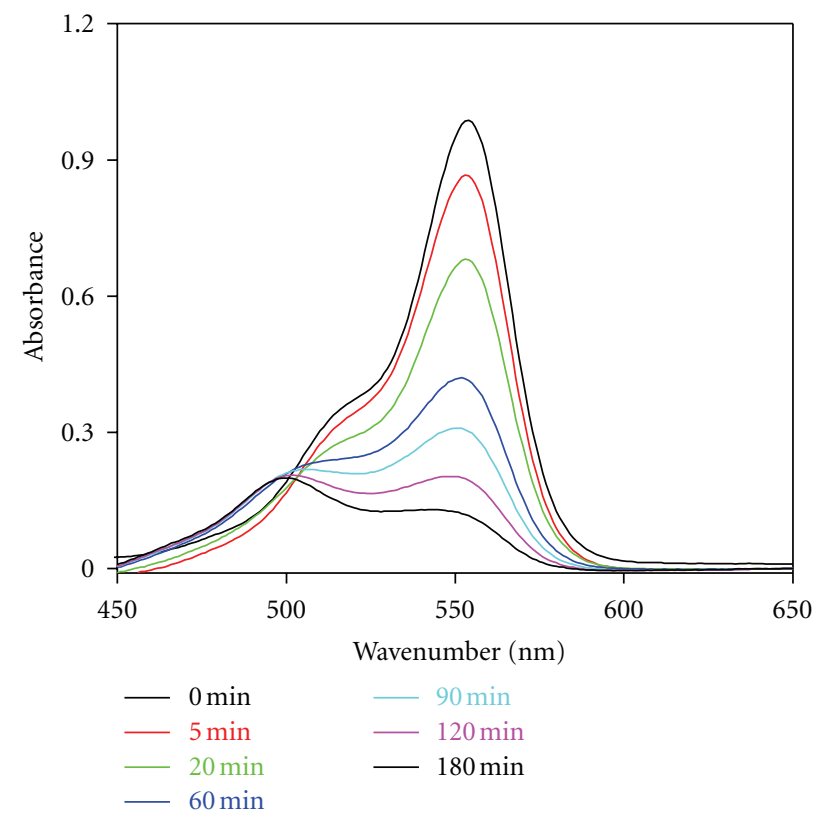

Figure 8: The dependence of absorbance $(A)$ of RhB aqueous solution on the visible-light irradiation time.

tion peak of $\mathrm{RhB}$ aqueous solution is very weak and the color of the $\mathrm{RhB}$ aqueous solution changes from orange to near no color, indicating that the $\mathrm{Au}-\mathrm{TiO}_{2}$ composite powders can completely decolorize $\mathrm{RhB}$ aqueous solution under visiblelight irradiation. Usually, the complete decolorization of $\mathrm{RhB}$ requires a long time due to the fact that its decolorization goes through two different stages: the ring cleavage in the initial photocatalytic degradation stage and subsequent oxidation of the fragments in the latter stage $[40,58]$. Therefore, these composite powders prepared by this method could be useful for environmental applications such as air purification, water disinfection and purification, and hazardous waste remediation due to their cheap preparation process, controllable structure, large specific surface area, and high visible-light photocatalytic activity.

\section{Conclusions}

$\mathrm{Au}-\mathrm{TiO}_{2}$ nanocomposites can be facilely prepared by a simple spray hydrolytic method and assisted with photoreduction technique at $90^{\circ} \mathrm{C}$. The light absorption, the 
formation rates of hydroxyl radicals, and photocatalytic decolorization of $\mathrm{RhB}$ aqueous solution were significantly enhanced by those embeded $\mathrm{Au}$ nanoparticles in the $\mathrm{Au}$ $\mathrm{TiO}_{2}$ nanocomposites due to surface plasmon resonance of Au nanoparticles. The composite $R_{\mathrm{Au}}-0.015$ sample exhibited the best visible-light photocatalytic activity for photocatalytic decolorization of $\mathrm{RhB}$ aqueous solution due to the synergistic effects of the absorption shift into visible and improved efficiency of interfacial charge transfer process.

\section{Acknowledgments}

This paper was partially supported by the National Natural Science Foundation of China (51072154 and 51102190), Natural Science Foundation of Hubei Province (2010CDA078), National Basic Research Program of China (2009CB939704), and Self-determined and Innovative Research Funds of SKLWUT. This paper was also supported by the Key Science Research Project of the Hubei Provincial Department of Education (D20112107) and the Science Research Project of Hubei University of Medicine (2009QDJ25).

\section{References}

[1] A. Fujishima and K. Honda, "Electrochemical photolysis of water at a semiconductor electrode," Nature, vol. 238, no. 5358, pp. 37-38, 1972.

[2] M. A. Fox and M. T. Dulay, "Heterogeneous photocatalysis," Chemical Reviews, vol. 93, no. 1, pp. 341-357, 1993.

[3] M. R. Hoffmann, S. T. Martin, W. Choi, and D. W. Bahnemann, "Environmental applications of semiconductor photocatalysis," Chemical Reviews, vol. 95, no. 1, pp. 69-96, 1995.

[4] J. Zhou, Y. Cheng, and J. Yu, "Preparation and characterization of visible-light-driven plasmonic photocatalyst $\mathrm{Ag} / \mathrm{AgCl} / \mathrm{TiO}_{2}$ nanocomposite thin films," Journal of Photochemistry and Photobiology A, vol. 223, no. 2-3, pp. 82-87, 2011.

[5] J. Yu, T. Ma, and S. Liu, "Enhanced photocatalytic activity of mesoporous $\mathrm{TiO}_{2}$ aggregates by embedding carbon nanotubes as electron-transfer channel," Physical Chemistry Chemical Physics, vol. 13, no. 8, pp. 3491-3501, 2011.

[6] J. Yu, Y. Su, and B. Cheng, "Template-free fabrication and enhanced photocatalytic activity of hierarchical macro/mesoporous titania," Advanced Functional Materials, vol. 17, no. 12, pp. 1984-1990, 2007.

[7] S. Wang, L. Zhao, J. Ran, Z. Shu, G. Dai, and P. Zhai, "Effects of calcination temperatures on photocatalytic activity of ordered titanate nanoribbon $/ \mathrm{SnO}_{2}$ films fabricated during an EPD process," International Journal of Photoenergy, vol. 2012, Article ID 472958, 7 pages, 2012.

[8] H. Fu, G. Shang, S. Yang, and T. Xu, "Mechanistic study of visible-light-induced photodegradation of 4-chlorophenol by $\mathrm{TiO}_{2-X} \mathrm{~N}_{X}(0.021<x<0.049)$ with low nitrogen concentration," International Journal of Photoenergy, vol. 2012, Article ID 759306, 9 pages, 2012.

[9] S.-J. Kim, N.-H. Lee, H.-J. Oh, S.-C. Jung, W.-J. Lee, and D.-H. Kim, "Photocatalytic properties of nanotubular-shaped $\mathrm{TiO}_{2}$ powders with anatase phase obtained from titanate nanotube powder through various thermal treatments," International Journal of Photoenergy, vol. 2011, Article ID 327821, 7 pages, 2011.
[10] J. A. Byrne, P. A. Fernandez-Ibañez, P. S. M. Dunlop, D. M. A. Alrousan, and J. W. J. Hamilton, "Photocatalytic enhancement for solar disinfection of water: a review," International Journal of Photoenergy, vol. 2011, Article ID 798051, 12 pages, 2011.

[11] W.-C. Oh and M.-L. Chen, "The improved photocatalytic properties of methylene blue for $\mathrm{V}_{2} \mathrm{O}_{3} / \mathrm{CNT} / \mathrm{TiO}_{2}$ composite under visible light," International Journal of Photoenergy, vol. 2010, Article ID 264831, 5 pages, 2010.

[12] Z. Zhang and J. Gamage, "Applications of photocatalytic disinfection," International Journal of Photoenergy, vol. 2010, Article ID 764870, 11 pages, 2010.

[13] T. Hirakawa and P. V. Kamat, "Charge separation and catalytic activity of Ag@ $\mathrm{TiO}_{2}$ core-shell composite clusters under UVirradiation," Journal of the American Chemical Society, vol. 127, no. 11, pp. 3928-3934, 2005.

[14] P. Mulvaney, "Surface plasmon spectroscopy of nanosized metal particles," Langmuir, vol. 12, no. 3, pp. 788-800, 1996.

[15] Q. Xiang, J. Yu, B. Cheng, and H. C. Ong, "Microwavehydrothermal preparation and visible-light photoactivity of plasmonic photocatalyst $\mathrm{Ag}-\mathrm{TiO}_{2}$ nanocomposite hollow spheres," Chemistry - An Asian Journal, vol. 5, no. 6, pp. 1466$1474,2010$.

[16] B. Cheng, Y. Le, and J. Yu, "Preparation and enhanced photocatalytic activity of $\mathrm{Ag} @ \mathrm{TiO}_{2}$ core-shell nanocomposite nanowires," Journal of Hazardous Materials, vol. 177, no. 1-3, pp. 971-977, 2010.

[17] J. J. Mock, M. Barbic, D. R. Smith, D. A. Schultz, and S. Schultz, "Shape effects in plasmon resonance of individual colloidal silver nanoparticles," Journal of Chemical Physics, vol. 116, no. 15, pp. 6755-6759, 2002.

[18] R. Jin, Y. C. Cao, E. Hao, G. S. Métraux, G. C. Schatz, and C. A. Mirkin, "Controlling anisotropic nanoparticle growth through plasmon excitation," Nature, vol. 425, no. 6957, pp. 487-490, 2003.

[19] F. Kim, J. H. Song, and P. Yang, "Photochemical synthesis of gold nanorods," Journal of the American Chemical Society, vol. 124, no. 48, pp. 14316-14317, 2002.

[20] M. Jakob, H. Levanon, and P. V. Kamat, "Charge distribution between UV-irradiated $\mathrm{TiO}_{2}$ and gold nanoparticles: determination of shift in the Fermi level," Nano Letters, vol. 3, no. 3, pp. 353-358, 2003.

[21] V. Subramanian, E. E. Wolf, and P. V. Kamat, "Catalysis with $\mathrm{TiO}_{2} /$ gold nanocomposites. Effect of metal particle size on the fermi level equilibration," Journal of the American Chemical Society, vol. 126, no. 15, pp. 4943-4950, 2004.

[22] Y. Tian and T. Tatsuma, "Mechanisms and applications of plasmon-induced charge separation at $\mathrm{TiO}_{2}$ films loaded with gold nanoparticles," Journal of the American Chemical Society, vol. 127, no. 20, pp. 7632-7637, 2005.

[23] L. Xiao, J. Zhang, Y. Cong, B. Tian, F. Chen, and M. Anpo, "Synergistic effects of doped $\mathrm{Fe}(3+)$ and deposited $\mathrm{Au}$ on improving the photocatalytic activity of $\mathrm{TiO}_{2}$," Catalysis Letters, vol. 111, no. 3-4, pp. 207-211, 2006.

[24] R. S. Sonawane and M. K. Dongare, "Sol-gel synthesis of $\mathrm{Au} / \mathrm{TiO}_{2}$ thin films for photocatalytic degradation of phenol in sunlight," Journal of Molecular Catalysis A, vol. 243, no. 1, pp. 68-76, 2006.

[25] V. Iliev, D. Tomova, L. Bilyarska, and G. Tyuliev, "Influence of the size of gold nanoparticles deposited on $\mathrm{TiO}_{2}$ upon the photocatalytic destruction of oxalic acid," Journal of Molecular Catalysis A, vol. 263, no. 1-2, pp. 32-38, 2007.

[26] F. B. Li, X. Z. Li, and M. F. Hou, "Photocatalytic degradation of 2-mercaptobenzothiazole in aqueous $\mathrm{La}^{3+}-\mathrm{TiO}_{2}$ suspension 
for odor control," Applied Catalysis B, vol. 48, no. 3, pp. 185194, 2004.

[27] D. I. Enache, J. K. Edwards, P. Landon et al., "Solvent-free oxidation of primary alcohols to aldehydes using $\mathrm{Au}-\mathrm{Pd} / \mathrm{TiO}_{2}$ catalyst," Science, vol. 311, no. 5759, pp. 362-365, 2006.

[28] F. Boccuzzi, A. Chiorino, M. Manzoli et al., "Au/ $/ \mathrm{TiO}_{2}$ nanosized samples: a catalytic, TEM, and FTIR study of the effect of calcination temperature on the CO oxidation," Journal of Catalysis, vol. 202, no. 2, pp. 256-267, 2001.

[29] M. Daté and M. Haruta, "Moisture effect on CO oxidation over $\mathrm{Au} / \mathrm{TiO}_{2}$ catalyst," Journal of Catalysis, vol. 201, no. 2, pp. 221-224, 2001.

[30] X. Z. Li and F. B. Li, "Study of $\mathrm{Au} / \mathrm{Au}^{3+}-\mathrm{TiO}_{2}$ photocatalysts toward visible photooxidation for water and wastewater treatment," Environmental Science and Technology, vol. 35, no. 11, pp. 2381-2387, 2001.

[31] N. Lopez, J. K. Nørskov, T. V. W. Janssens et al., "The adhesion and shape of nanosized $\mathrm{Au}$ particles in a $\mathrm{Au} / \mathrm{TiO}_{2}$ catalyst," Journal of Catalysis, vol. 225, no. 1, pp. 86-94, 2004.

[32] I. M. Arabatzis, T. Stergiopoulos, D. Andreeva, S. Kitova, S. G. Neophytides, and P. Falaras, "Characterization and photocatalytic activity of $\mathrm{Au} / \mathrm{TiO}_{2}$ thin films for azo-dye degradation," Journal of Catalysis, vol. 220, no. 1, pp. 127-135, 2003.

[33] V. Subramanian, E. E. Wolf, and P. V. Kamat, "Influence of metal/metal ion concentration on the photocatalytic activity of $\mathrm{TiO}_{2}$ - Au composite nanoparticles," Langmuir, vol. 19, no. 2, pp. 469-474, 2003.

[34] M. Epifani, C. Giannini, L. Tapfer, and L. Vasanelli, "Sol-gel synthesis and characterization of $\mathrm{Ag}$ and $\mathrm{Au}$ nanoparticles in $\mathrm{SiO}_{2}, \mathrm{TiO}_{2}$, and $\mathrm{ZrO}_{2}$ thin films," Journal of the American Ceramic Society, vol. 83, no. 10, pp. 2385-2393, 2000.

[35] M. Zhou, J. Yu, S. Liu, P. Zhai, and B. Huang, "Sprayhydrolytic synthesis of highly photoactive mesoporous anatase nanospheres for the photocatalytic degradation of toluene in air," Applied Catalysis B, vol. 89, no. 1-2, pp. 160-166, 2009.

[36] K. S. Sing, D. H. Everett, R. A. W. Haul et al., "Reporting physisorption data for gas/solid sysytems," Pure and Applied Chemistry, vol. 57, no. 4, pp. 603-619.

[37] J. Yu, W. Wang, B. Cheng, and B. L. Su, "Enhancement of photocatalytic activity of Mesporous $\mathrm{TiO}_{2}$ powders by hydrothermal surface fluorination treatment," Journal of Physical Chemistry C, vol. 113, no. 16, pp. 6743-6750, 2009.

[38] J. Yu, Q. Xiang, and M. Zhou, "Preparation, characterization and visible-light-driven photocatalytic activity of Fe-doped titania nanorods and first-principles study for electronic structures," Applied Catalysis B, vol. 90, no. 3-4, pp. 595-602, 2009.

[39] K. I. Ishibashi, A. Fujishima, T. Watanabe, and K. Hashimoto, "Detection of active oxidative species in $\mathrm{TiO}_{2}$ photocatalysis using the fluorescence technique," Electrochemistry Communications, vol. 2, no. 3, pp. 207-210, 2000.

[40] J. Yu and X. Yu, "Hydrothermal synthesis and photocatalytic activity of zinc oxide hollow spheres," Environmental Science and Technology, vol. 42, no. 13, pp. 4902-4907, 2008.

[41] M. Zhou, J. Yu, S. Liu, P. Zhai, and L. Jiang, "Effects of calcination temperatures on photocatalytic activity of $\mathrm{SnO}_{2} / \mathrm{TiO}_{2}$ composite films prepared by an EPD method," Journal of Hazardous Materials, vol. 154, no. 1-3, pp. 11411148, 2008.

[42] H. Takahashi, I. Harrowfield, C. MacRae, N. Wilson, and K. Tsutsumi, "Analytical TEM study on the dispersion of $\mathrm{Au}$ nanoparticles in $\mathrm{Au} / \mathrm{TiO}_{2}$ catalyst prepared under various temperatures," Surface and Interface Analysis, vol. 31, no. 2, pp. 73-78, 2001.

[43] T. Akita, K. Tanaka, S. Tsubota, and M. Haruta, "Analytical high-resolution TEM study of supported gold catalysts: orientation relationship between Au particles and $\mathrm{TiO}_{2}$ supports," Journal of Electron Microscopy, vol. 49, no. 5, pp. 657-662, 2000.

[44] J. Yu, L. Yue, S. Liu, B. Huang, and X. Zhang, "Hydrothermal preparation and photocatalytic activity of mesoporous Au$\mathrm{TiO}_{2}$ nanocomposite microspheres," Journal of Colloid and Interface Science, vol. 334, no. 1, pp. 58-64, 2009.

[45] J. Yu, J. Xiong, B. Cheng, and S. Liu, "Fabrication and characterization of $\mathrm{Ag}-\mathrm{TiO}_{2}$ multiphase nanocomposite thin films with enhanced photocatalytic activity," Applied Catalysis B, vol. 60, no. 3-4, pp. 211-221, 2005.

[46] J. Yu, H. Tao, and B. Cheng, "In situ monitoring of heterogeneous catalytic reactions," ChemPhysChem, vol. 11, no. 8, pp. 1617-1618, 2010.

[47] J. Yu, G. Dai, and B. Huang, "Fabrication and characterization of visible-light-driven plasmonic photocatalyst $\mathrm{Ag} / \mathrm{AgCl} / \mathrm{TiO}_{2}$ nanotube arrays," Journal of Physical Chemistry C, vol. 113, no. 37, pp. 16394-16401, 2009.

[48] T. Diemant, Z. Zhao, H. Rauscher, J. Bansmann, and R. J. Behm, "Interaction of $\mathrm{CO}$ with planar $\mathrm{Au} / \mathrm{TiO}_{2}$ model catalysts at elevated pressures," Topics in Catalysis, vol. 44, no. 1-2, pp. 83-93, 2007.

[49] A. Zwijnenburg, A. Goossens, W. G. Sloof et al., "XPS and Mössbauer characterization of $\mathrm{Au} / \mathrm{TiO}_{2}$ propene epoxidation catalysts," Journal of Physical Chemistry B, vol. 106, no. 38, pp. 9853-9862, 2002.

[50] Y. Zhang, G. Li, Y. Wu, Y. Luo, and L. Zhang, "The formation of mesoporous $\mathrm{TiO}_{2}$ spheres via a facile chemical process," Journal of Physical Chemistry B, vol. 109, no. 12, pp. 54785481, 2005.

[51] Z. Liu, D. D. Sun, P. Guo, and J. O. Leckie, "One-step fabrication and high photocatalytic activity of porous $\mathrm{TiO}_{2}$ hollow aggregates by using a low-temperature hydrothermal method without templates," Chemistry, vol. 13, no. 6, pp. 1851-1855, 2007.

[52] Q. Li, B. Guo, J. Yu et al., "Highly efficient visible-lightdriven photocatalytic hydrogen production of CdS-clusterdecorated graphene nanosheets," Journal of the American Chemical Society, vol. 133, no. 28, pp. 10878-10884, 2011.

[53] Q. Xiang, J. Yu, and M. Jaroniec, "Enhanced photocatalytic $\mathrm{H}_{2}$-production activity of graphene-modified titania nanosheets," Nanoscale, vol. 3, no. 9, pp. 3670-3678, 2011.

[54] R. K. Rana, Y. Mastai, and A. Gedanken, "Acoustic cavitation leading to the morphosynthesis of mesoporous silica vesicles," Advanced Materials, vol. 14, no. 19, pp. 1414-1418, 2002.

[55] P. Madhusudan, J. Ran, J. Zhang, J. Yu, and G. Liu, "Novel urea assisted hydrothermal synthesis of hierarchical $\mathrm{BiVO}_{4} / \mathrm{Bi}_{2} \mathrm{O}_{2} \mathrm{CO}_{3}$ nanocomposites with enhanced visible-light photocatalytic activity," Applied Catalysis B, vol. 110, pp. 286295, 2011.

[56] J. Yu, L. Zhang, B. Cheng, and Y. Su, "Hydrothermal preparation and photocatalytic activity of hierarchically sponge-like macro-/mesoporous Titania," Journal of Physical Chemistry C, vol. 111, no. 28, pp. 10582-10589, 2007.

[57] Q. Xiang, J. Yu, and M. Jaroniec, "Nitrogen and sulfur codoped $\mathrm{TiO}_{2}$ nanosheets with exposed 001 facets: synthesis, characterization and visible-light photocatalytic activity," Physical Chemistry Chemical Physics, vol. 13, no. 11, pp. 48534861, 2011. 
[58] H. Fu, C. Pan, W. Yao, and Y. Zhu, "Visible-light-induced degradation of rhodamine $\mathrm{B}$ by nanosized $\mathrm{Bi}_{2} \mathrm{WO}_{6}$," Journal of Physical Chemistry B, vol. 109, no. 47, pp. 22432-22439, 2005. 


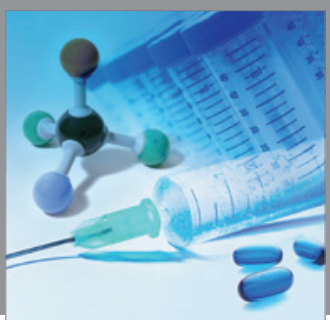

International Journal of

Medicinal Chemistry

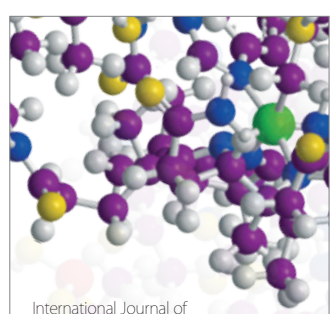

Carbohydrate Chemistry

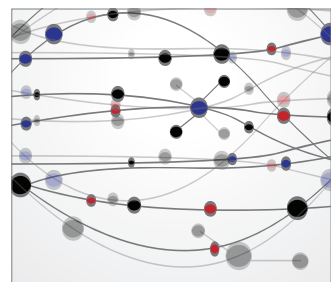

The Scientific World Journal
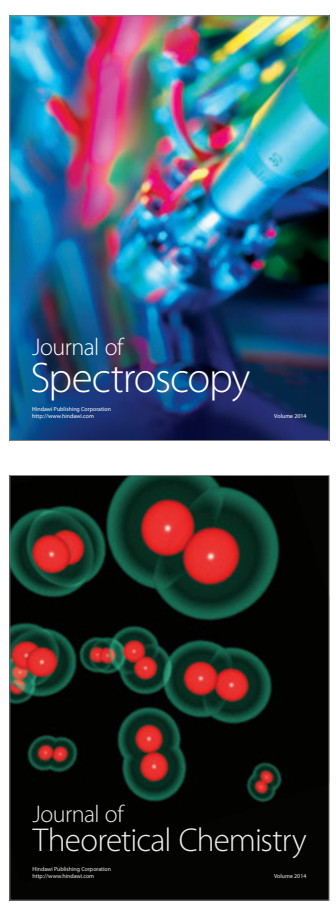
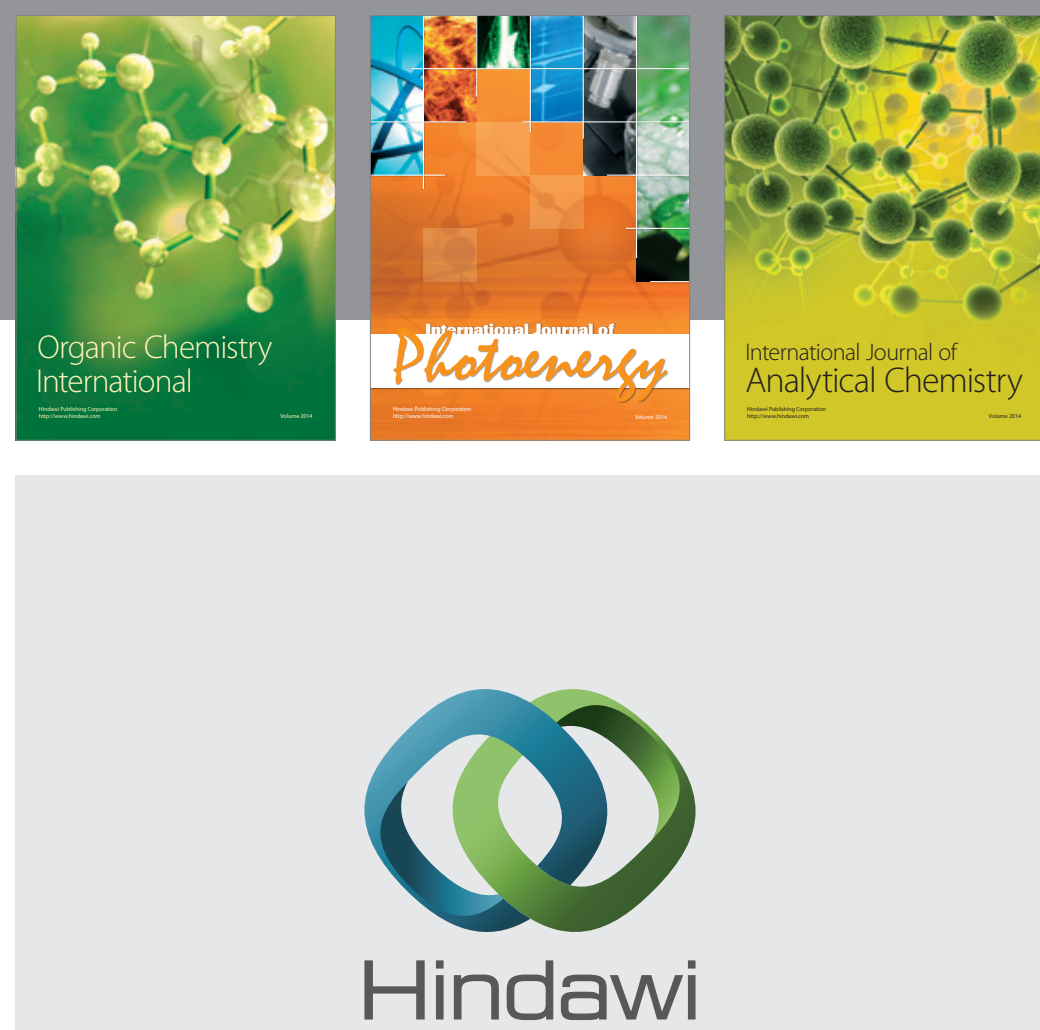

Submit your manuscripts at

http://www.hindawi.com
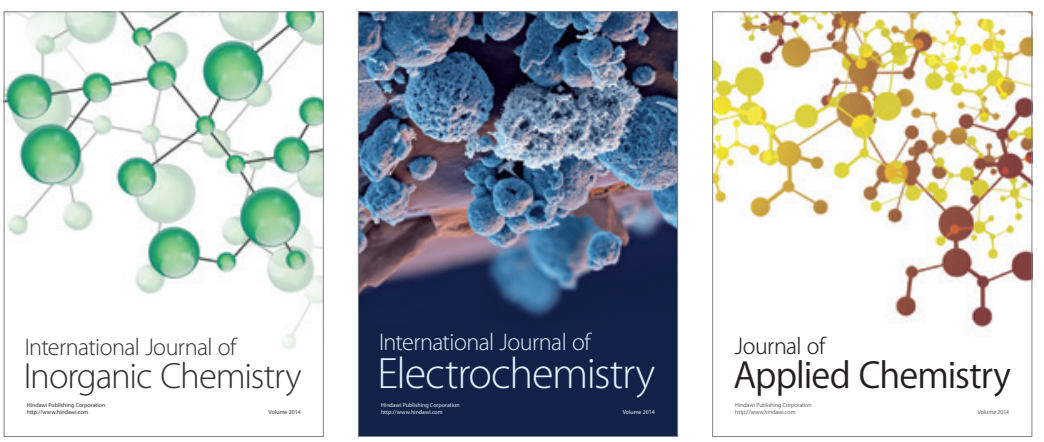

Journal of

Applied Chemistry
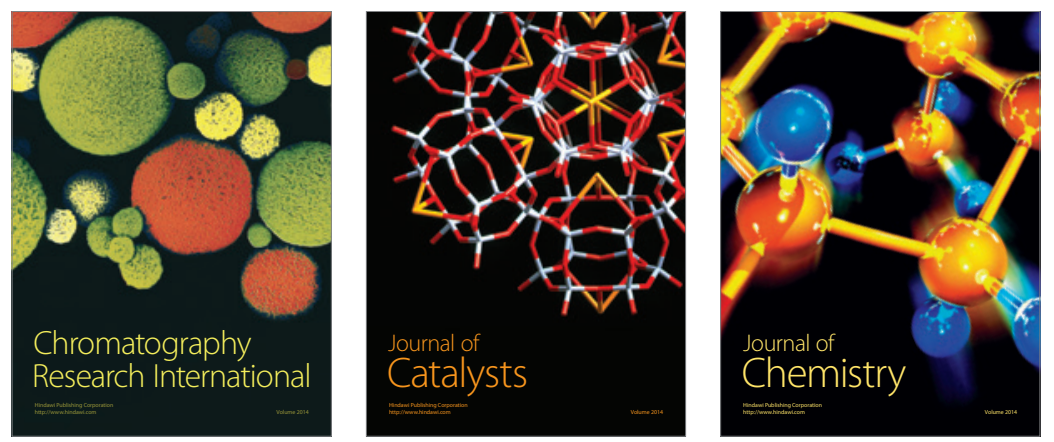
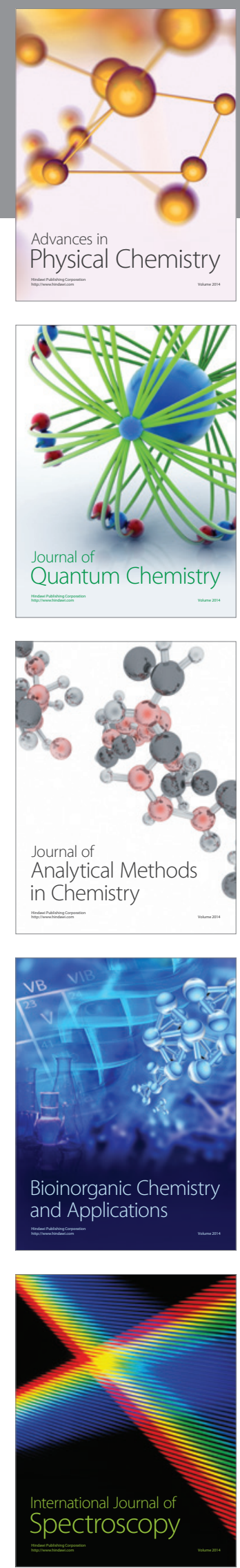